\title{
Effect of $\mathrm{Ag}$ additions on the $\beta$ phase formation reaction in the $\mathrm{Cu}-9$ wt.\%Al-6 wt.\%Mn alloy
}

\author{
A.T. Adorno $^{\text {a,*, T.M. Carvalho }}{ }^{\text {a }}$, R.A.G. Silva ${ }^{\text {b }}$, C.M.A. Santos ${ }^{\text {a }}$, A.G. Magdalena ${ }^{\text {a }}$ \\ a Departamento de Físico-Química, Instituto de Química, UNESP, Caixa Postal 355, 14801-970 Araraquara, SP, Brazil \\ ${ }^{\mathrm{b}}$ Departamento de Ciências Exatas e da Terra, UNIFESP, 09972-270 Diadema, SP, Brazil
}

\section{A R T I C L E I N F O}

\section{Article history:}

Available online 7 October 2014

\section{Keywords:}

Metals and alloys

Solid state reactions

Kinetics

Thermal analysis

\begin{abstract}
A B S T R A C T
The influence of 4 and $5 \mathrm{wt} . \% \mathrm{Ag}$ additions on the kinetics of $\beta\left[\mathrm{T}_{7}-(\mathrm{CuMn})_{3} \mathrm{Al}\right]$ phase formation reaction in the Cu-9 wt.\%Al-6 wt.\%Mn alloy was studied using differential scanning calorimetry (DSC), X-ray diffractometry (XRD) and scanning electron microscopy (SEM). The results indicate that the conversion dependence of the activation energy has a descending shape, suggesting a multi-step process involving reversible reactions. The presence of $\mathrm{Ag}$ facilitates the formation of the $\beta$ phase. The results also showed that the $\mathrm{Ag}$ precipitates formation includes the dissolution of $\mathrm{Mn}$ and $\mathrm{Al}$ atoms, thus decreasing the partial fraction of these elements available to react.
\end{abstract}

(c) 2014 Elsevier B.V. All rights reserved.

\section{Introduction}

The $\mathrm{Cu}-\mathrm{Al}$ system shows a $\beta$ bcc disordered phase, stable at high temperatures. The stability range becomes smaller at lower temperatures, showing an eutectoid point around $560{ }^{\circ} \mathrm{C}$ for around $12 \mathrm{wt} . \% \mathrm{Al}$. At temperatures below the range of stability of the $\beta$ phase, shows the stable phases: $\alpha$ and $\gamma-\mathrm{Cu}_{9} \mathrm{Al}_{4}$ [1]. Additions of $\mathrm{Ag}$ to $\mathrm{Cu}-\mathrm{Al}$ alloys can improve its corrosion resistance [2], increase its hardness and influence the nucleation rate and the activation energy of the eutectoid decomposition reaction [3]. The phases of the $\mathrm{Cu}-\mathrm{Al}-\mathrm{Ag}$ system are structurally similar to those present in the binary $\mathrm{Cu}-\mathrm{Al}$ system without intermediate ternary phases [4]. The addition of $\mathrm{Mn}$ to the $\mathrm{Cu}-\mathrm{Al}$ system gives to this system some interesting properties, for example, increases the stability of the bcc $\beta$ phase in relation to the diffusional decomposition and slows down this decomposition when the phase becomes a metastable $\beta$, which allows most suitable properties associated with the shape memory effect [5]. For kinetic reasons, this $\beta$ phase can be retained below its stability limit by means of a suitable cooling. The metastable $\beta$ phase orders during cooling and, for certain compositions, undergoes at a lower temperature a first-order and diffusionless transition. This transition is known as the martensitic transformation, and has received a great deal of attention in recent years because it is the origin of shape memory properties, which confer a considerable technological importance on these systems [5]. In this wok, the influence of $\mathrm{Ag}$

\footnotetext{
* Corresponding author. Tel.: +55 163301 9639; fax: +55 1633222308 .

E-mail address: atadorno@iq.unesp.br (A.T. Adorno).
}

on the $\beta$ phase formation reaction of the $\mathrm{Cu}-9 \mathrm{wt} . \% \mathrm{Al}-6 \mathrm{wt} . \% \mathrm{Mn}$ alloy was studied using differential scanning calorimetry (DSC), X-ray diffractometry (XRD), scanning electron microscopy (SEM) and energy dispersive X-ray spectroscopy (EDS).

\section{Material and methods}

The alloys were prepared in an Johanna Otto Arc Melting electric furnace Model D72379 coupled with vacuum equipment, using 99.95\% copper, 99.95\% manganese, 99.97\% aluminum and $99.98 \%$ silver as starting materials. Results from chemical analysis indicated a final alloy composition very close to the nominal one, with $\mathrm{Pb}, \mathrm{Fe}$, and $\mathrm{Mn}$ as main impurities (concentration less than $100 \mathrm{ppm}$ ). Cylindrical samples of $20 \mathrm{~mm}$ diameter and $60 \mathrm{~mm}$ length were cut in disks of $2.0 \mathrm{~mm}$ thickness. The disks were cold rolled and flat square samples of $1.0 \mathrm{~mm}$ thickness and about $5.0 \mathrm{~mm}$ length were used for scanning electron microscopy (SEM) and X-ray diffractometry (XRD). All samples were annealed during $120 \mathrm{~h}$ at $850{ }^{\circ} \mathrm{C}$ for homogenization. After the heat treatment the samples were polished, etched and the phases present in the studied alloys were identified and characterized by $\mathrm{X}$-ray diffraction using a Siemens D5000 diffractometer with filtered CuK radiation in solid (not powdered) samples and by scanning electron microscopy using a Philips XL30 FEG, equipped with an Oxford analyzer. DSC curves were obtained using a Q20 TA instrument, platinum pan, nitrogen flux at about $50 \mathrm{~mL} \mathrm{~min}^{-1}$ and solid samples with $3.0 \mathrm{~mm}$ diameter.

\section{Results and discussion}

Fig. 1 shows the DSC curves obtained at different heating rates for the $\mathrm{Cu}-9$ wt.\%Al-6 wt.\%Mn, Cu-9 wt.\%Al-6 wt.\%Mn-4 wt.\%Ag and $\mathrm{Cu}-9 \mathrm{wt} . \% \mathrm{Al}-6 \mathrm{wt} . \% \mathrm{Mn}-5 \mathrm{wt} . \% \mathrm{Ag}$ alloys initially annealed. The starting point of these curves correspond to $\alpha-C u, T_{3}-C_{3} M_{2} A l$ and the Ag-rich phase, as shown in the first X-ray diffraction pattern of Fig. 2, obtained for the $\mathrm{Cu}-9 \mathrm{wt} . \% \mathrm{Al}-6 \mathrm{wt} . \% \mathrm{Mn}$ and 
(a)

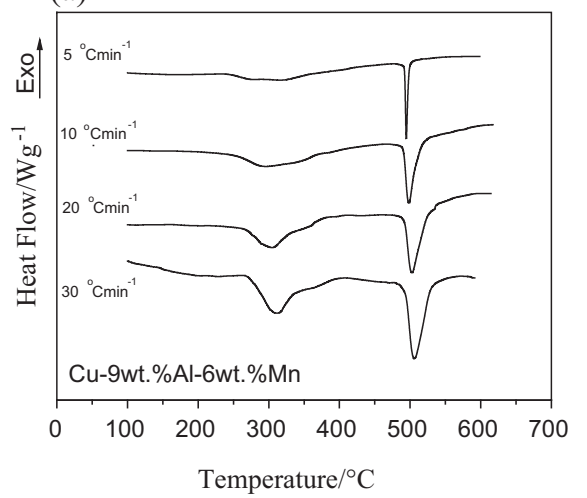

(b)

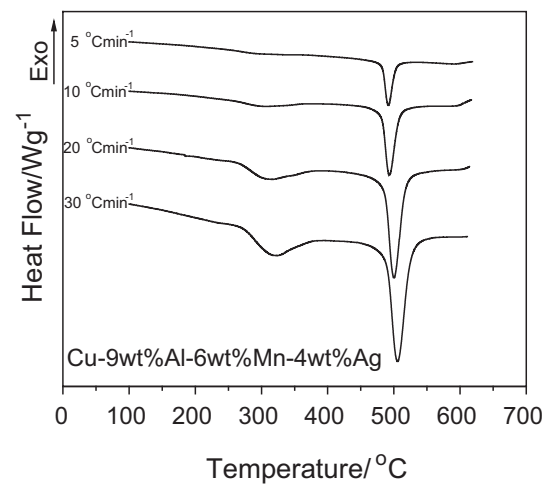

(c)

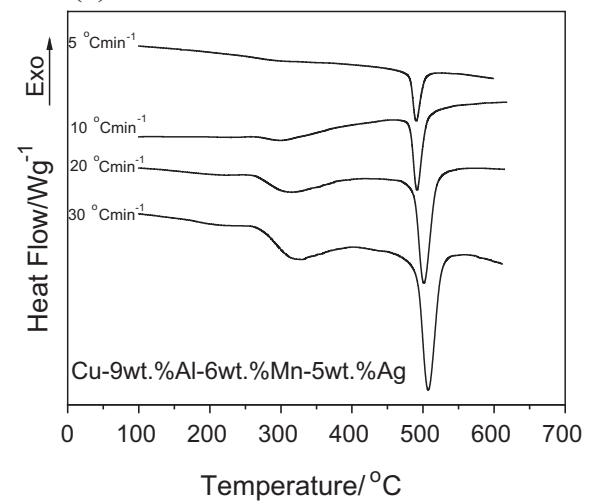

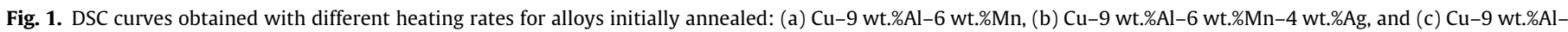
6 wt.\%Mn-5 wt.\%Ag.

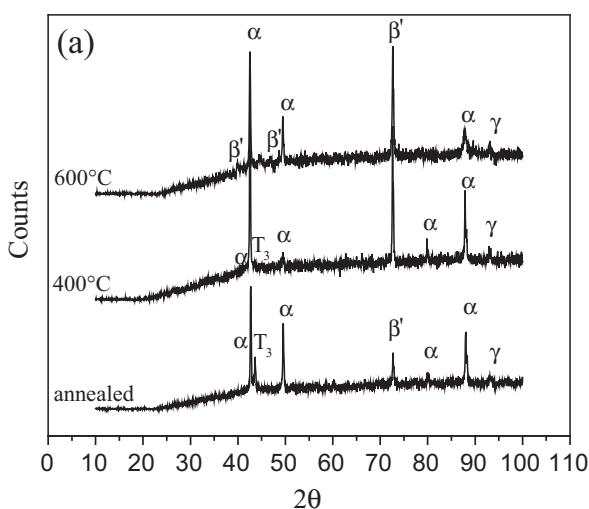

$2 \theta$

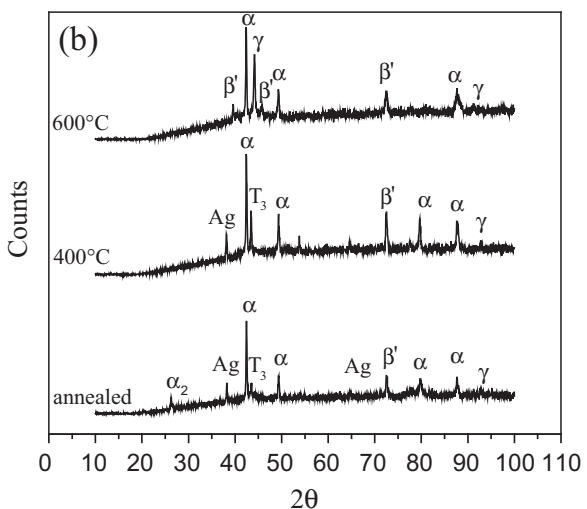

$2 \theta$

Fig. 2. X-ray diffraction patterns obtained for the (a) Cu-9 wt.\%Al-6 wt.\%Mn and (b) Cu-9 wt.\%Al-6 wt.\%Mn-4 wt.\%Ag.

Cu-9 wt.\%Al-6 wt.\%Mn-4 wt.\%Ag alloys after annealing. Similar Xray diffraction patterns were obtained for all other studied alloys. In Fig. 1a, corresponding to the $\mathrm{Cu}-9 \mathrm{wt} . \% \mathrm{Al}-6 \mathrm{wt} . \mathrm{Mn}$ alloy, it is possible to observe two endothermic peaks. The peak at about $300{ }^{\circ} \mathrm{C}$ is associated with the $\alpha_{2}$ disordering reaction and $\alpha+\gamma_{2}+\mathrm{T}_{3}-\mathrm{Cu}_{3} \mathrm{Mn}_{2} \mathrm{Al} \rightarrow \alpha+\gamma_{2}+\beta_{\mathrm{I}}$ reaction. The peak at about $500{ }^{\circ} \mathrm{C}$ is attributed to the $\alpha+\gamma_{2}+\beta_{\mathrm{I}} \rightarrow \alpha+\gamma_{2}+\beta\left[\mathrm{T}_{7}-(\mathrm{CuMn})_{3} \mathrm{Al}\right]$ transition [6-8]. These two peaks were observed for all studied alloys, as seen from Fig. $1 \mathrm{~b}$ and $\mathrm{c}$.

Fig. 2 shows the X-ray diffraction patterns obtained at 400 to $600{ }^{\circ} \mathrm{C}$ or just before and after the peak observed at $500{ }^{\circ} \mathrm{C}$ in the DSC curves of Fig. 1. From these patterns one may observe Ag-rich phase dissolution, consumption of the $\gamma_{2}$ phase and the starting of $\beta$ phase formation in the temperature range between 400 and $600{ }^{\circ} \mathrm{C}$. It is important to notice that, in the studied alloys, the $\beta$ phase cannot be retained at low temperature during quenched and the martensite phase is formed by a non-diffusive process. Therefore, martensite is detected on X-ray diffraction patterns instead of $\beta$ phase.

Fig. 3 shows the scanning electron micrographs obtained for the $\mathrm{Cu}-9$ wt.\%Al-6 wt.\%Mn initially annealed and then quenched from 400 and $600{ }^{\circ} \mathrm{C}$. The difference between these structures and those observed for the alloy with $\mathrm{Ag}$ additions is just the presence of Ag-rich precipitates (see Figs. 2 and 4). Fig. 4a shows the scanning electron micrograph obtained for the Cu-9 wt.\%Al-6 wt.\%Mn5 wt.\%Ag alloy initially annealed and then quenched from $400{ }^{\circ} \mathrm{C}$ and it is possible to observe some $\mathrm{Ag}$-rich precipitates, as indicated by the EDS spectrum in Fig. 4b. Fig. 4c shows the EDS mapping obtained on the line indicated in Fig. 4a. In this mapping it is possible to observe that $\mathrm{Al}$ and $\mathrm{Mn}$ concentrations are lower on the precipitate than on the matrix, as expected, and that the increase of $\mathrm{Ag}$ concentration on the precipitate corresponds to an almost symmetric decrease of $\mathrm{Cu}$ concentration, thus indicating an exchange between $\mathrm{Cu}$ and $\mathrm{Ag}$ atoms during precipitation. It is also observed that precipitates formation also includes the dissolution of $\mathrm{Mn}$ and $\mathrm{Al}$ atoms, thus decreasing the partial fraction of these elements available to react.

It is interesting to notice that, together with the $\mathrm{T}_{3}-\mathrm{Cu}_{3} \mathrm{Mn}_{2}$ $\mathrm{Al} \rightarrow \beta\left[\mathrm{T}_{7}-(\mathrm{Cu}, \mathrm{Mn}, \mathrm{Ag})_{3} \mathrm{Al}\right]$ transition, another reaction is occurring in the temperature range from $400{ }^{\circ} \mathrm{C}$ to $600{ }^{\circ} \mathrm{C}$. This can lead to a complex kinetic mechanism for this set of solid state reactions, considering that diffusion processes can be slower due to stronger interaction among the constituent atoms of alloys, thus increasing the activation energy. Therefore, the use of a kinetic model that gives information about the presence of different reaction steps is here needed.

Fig. 5 shows enlarged sections of the peak at about $500^{\circ} \mathrm{C}$ observed in Fig. 1. In this figure one may see that this peak is shifted to higher temperatures with the increase of the heating rate. The isoconversional method was used to obtain the activation energy for the reactions that occur in the temperature range from 465 to $530{ }^{\circ} \mathrm{C}$ for the $\mathrm{Cu}-9 \mathrm{wt} . \% \mathrm{Al}-6 \mathrm{wt} . \% \mathrm{Mn}, \mathrm{Cu}-9 \mathrm{wt} . \% \mathrm{Al}-$ 6 wt.\%Mn-4 wt.\%Ag and $\mathrm{Cu}-9$ wt.\%Al-6 wt.\%Mn-5 wt.\%Ag alloys. Considering the peak in Fig. 4 and the equation [9]: 
(a)

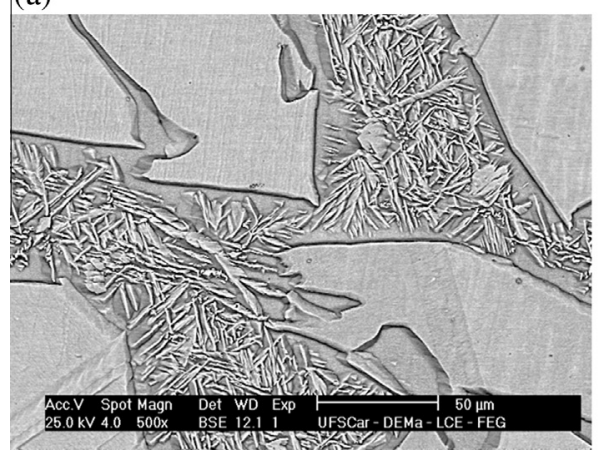

(b)

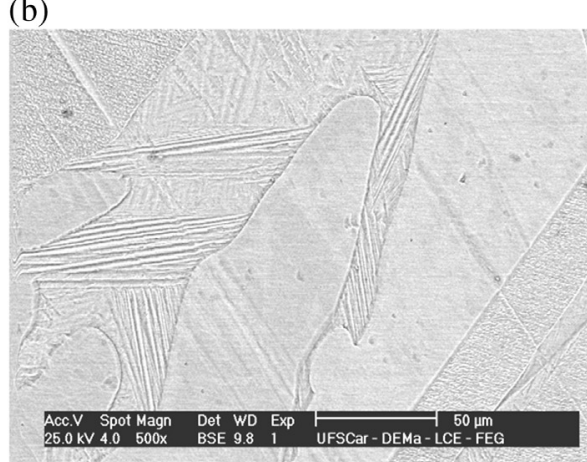

Fig. 3. Scanning electron micrographs obtained for the Cu-9 wt.\%Al-6 wt.\%Mn alloy initially annealed and then quenched from: (a) $400{ }^{\circ} \mathrm{C}$ and (b) $600{ }^{\circ} \mathrm{C}$.

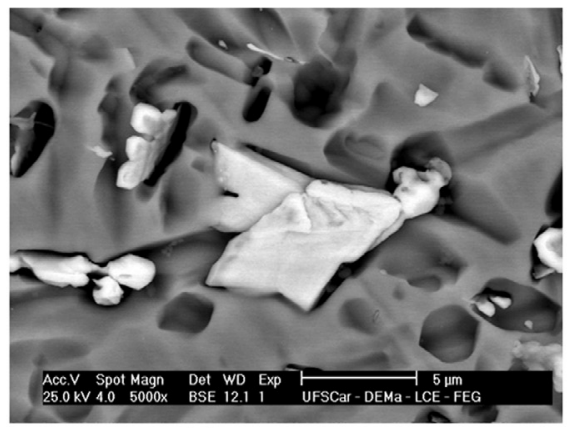

(a)

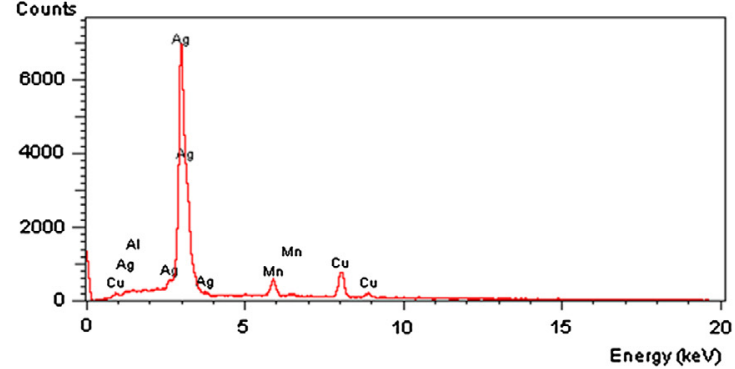

(b)
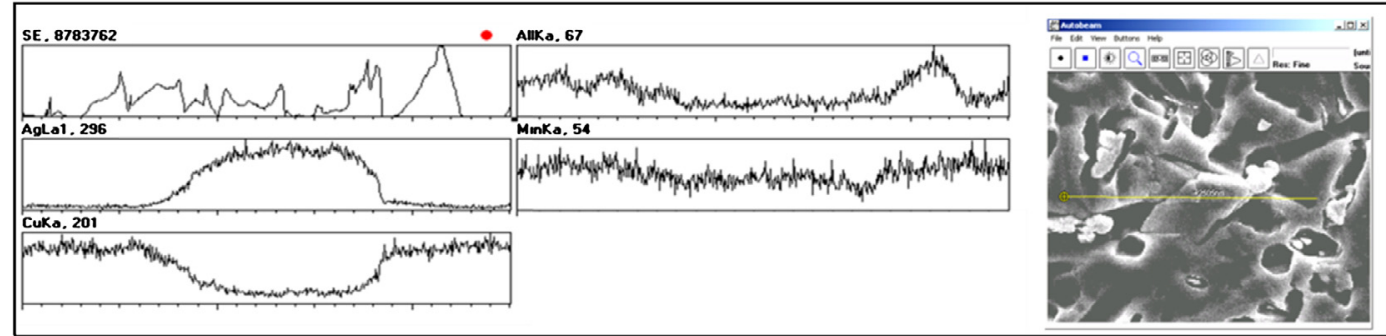

(c)

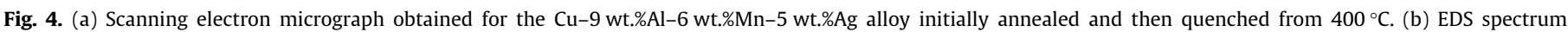
obtained on the precipitate (white region) in Fig. 2(a) and (c) EDS mapping of the sample on the line indicated in the micrograph in Fig. 3(a).

(a)

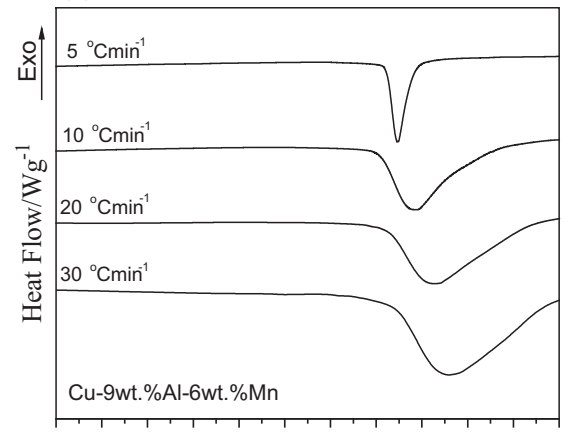

$420430440450460 \quad 470480490500510520530$

Temperature $/{ }^{\circ} \mathrm{C}$ (b)

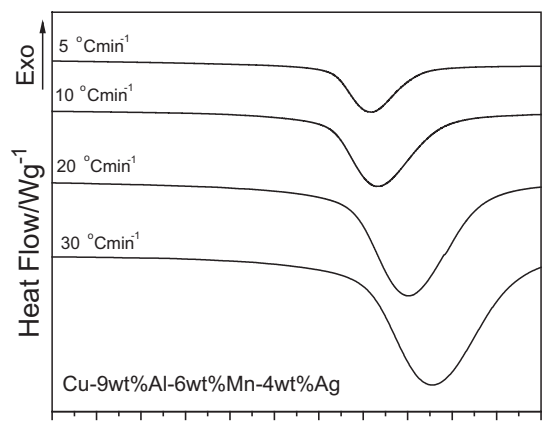

420430440450460470480490500510520530

Temperature $/{ }^{\circ} \mathrm{C}$ (c)

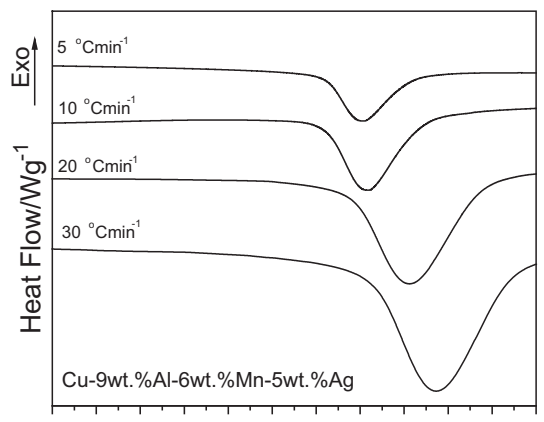

420430440450460470480490500510520530 Temperature/ ${ }^{\circ} \mathrm{C}$

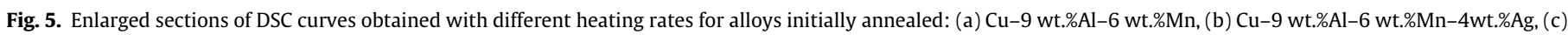
Cu-9 wt.\%Al-6 wt.\%Mn-5 wt.\%Ag. 
(a)

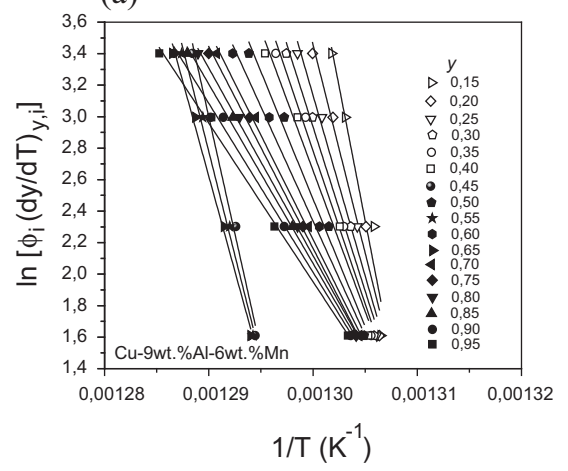

(b)

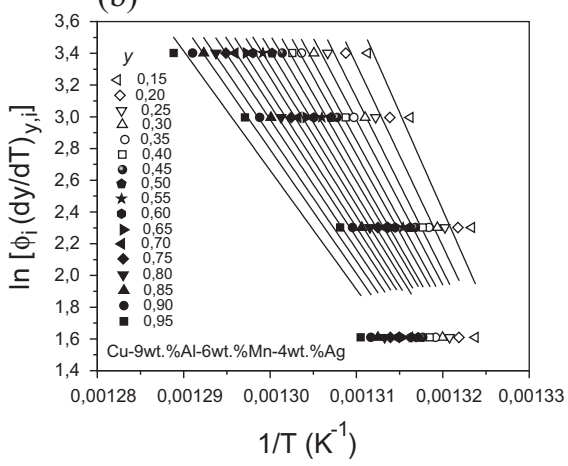

(c)

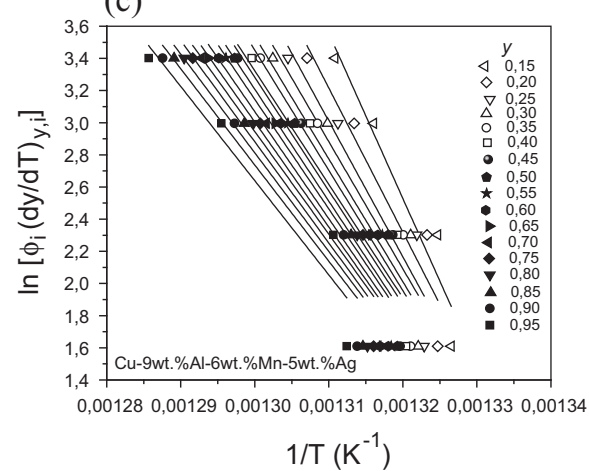

Fig. 6. Plots of $\ln \left[\phi_{i}(d y / d T)_{y, i}\right]$ against $1 / T_{y, i}$ for annealed alloys: (a) Cu-9 wt.\%Al-6 wt.\%Mn, (b) Cu-9 wt.\%Al-6 wt.\%Mn-4 wt.\%Ag, (c) Cu-9 wt.\%Al-6 wt.\%Mn-5 wt.\%Ag.

(a)

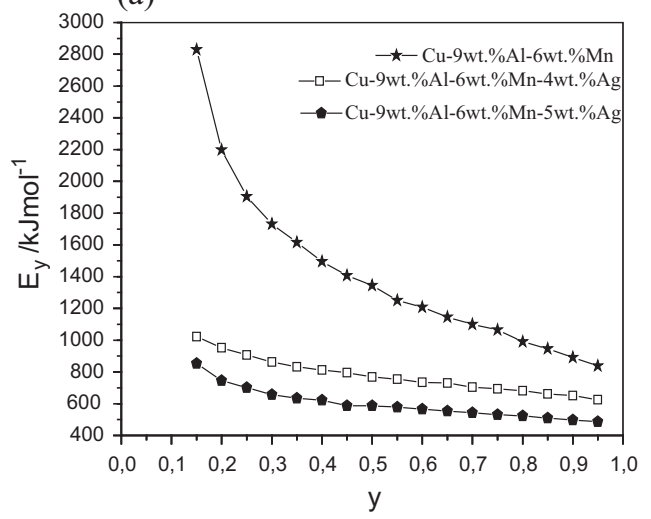

(b)

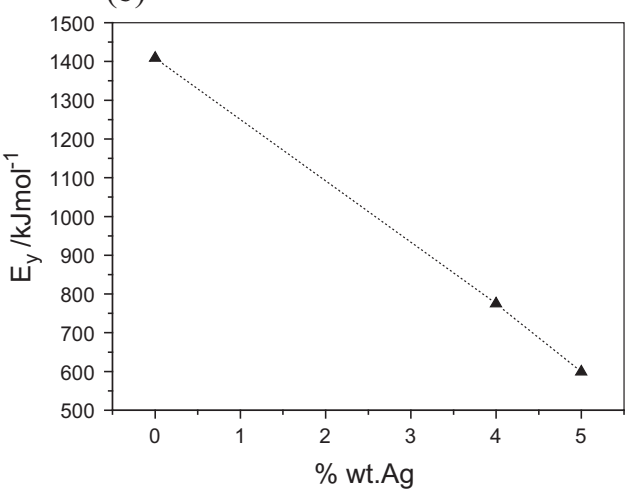

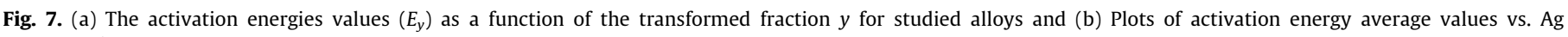
concentration.

$\ln \left[\phi_{i}\left(\frac{d y}{d T}\right)_{y, i}\right]=\ln \left[A_{y} f(y)\right]-\frac{E_{y}}{R T_{y, i}}$

where a subscript $y$ designates values related to a given conversion, and $i$ is a number of non-isothermal experiments conducted at the heating rate $\phi_{i}$, the value of $E_{y}$ for a given value $y$ can be obtained by plotting $\ln \left[\phi_{i}(d y / d T)_{y, i}\right]$ against $1 / T_{y, i}$. These plots are shown in Fig. 6 and $7 \mathrm{a}$. The plots in Fig. 7a indicates that the conversion dependence of the activation energy has a descending shape. This exponential decrease of the activation energy with the transformed fraction suggests a multi-step process involving reversible reactions [10].

In this way, the peak at about $500^{\circ} \mathrm{C}$ in Fig. 1 corresponds to a multiple step reaction, where the dissolution of the $\mathrm{T}_{3}$ and $\mathrm{Ag}$-rich phases has a remarkable influence on the $\beta\left[\mathrm{T}_{7}-(\mathrm{Cu}, \mathrm{Mn}, \mathrm{Ag})_{3} \mathrm{Al}\right]$ phase formation reaction. The mean values of the activation energy obtained for the studied alloys initially annealed were, respectively, 1409, 775 and $599 \mathrm{~kJ} \mathrm{~mol}^{-1}$, indicating that $\mathrm{Ag}$ additions decrease the activation energy for the process, as seen in Fig. $7 \mathrm{~b}$. The activation energy value for $\beta$ phase formation reaction decrease for the Cu-9 wt.\%Al-6 wt.\%Mn-4 wt.\%Ag and $\mathrm{Cu}-$ 9 wt.\%Al-6 wt.\%Mn-5 wt.\%Ag alloys when compared with $\mathrm{Cu}-$ 9 wt.\%Al-6 wt.\%Mn. Ag dissolution, at lower Ag concentrations, seems to occur preferably at the Mn, thus decreasing the fraction of this element available for the reaction and increasing the activation energy. For larger amounts of $\mathrm{Ag}, 4 \%$ and $5 \% \mathrm{Ag}$, the solubility limit of $\mathrm{Ag}$ into $\mathrm{Mn}$ must have been achieved and $\mathrm{Ag}$ dissolution occur preferably in the $\mathrm{Cu}$ matrix, thus increasing the $\mathrm{Al}$ fraction available for reaction and decreasing the activation energy for the process.

\section{Conclusions}

The isoconversional method was used to obtain the activation energy for the $\beta\left[\mathrm{T}_{7}-(\mathrm{CuMn})_{3} \mathrm{Al}\right]$ phase formation reaction in the Cu-9 wt.\%Al-6 wt.\%Mn, Cu-9 wt.\%Al-6 wt.\%Mn-4 wt.\%Ag and Cu-9 wt.\%Al-6 wt.\%Mn-5 wt.\%Ag alloys in the range $465-530^{\circ} \mathrm{C}$. The results indicate that the conversion dependence of the activation energy has a descending shape, suggesting a multi-step process involving reversible reactions. The $\mathrm{Ag}$ precipitates formation includes the dissolution of $\mathrm{Mn}$ and $\mathrm{Al}$ atoms, thus decreasing the partial fraction of these elements available to react. The results suggest that the remainder $\mathrm{Ag}$ solubilizes preferably at the $\mathrm{Cu}$ matrix, thus increasing the fraction of $\mathrm{Al}$ available for reaction and decreasing the activation energy for the process.

\section{Acknowledgements}

The authors thank FAPESP, CNPq and CAPES for financial support.

\section{References}

[1] R.A.G. Silva, A.T. Adorno, A.G. Magdalena, T.M. Carvalho, M. Stipcich, A. Cunibert, M.L. Castro, Thermal behavior of the $\mathrm{Cu}-22.55$ at.\%Al alloy with small Ag additions, J. Therm. Anal. Calorim. 103 (2011) 459-463. 
[2] J.M.G. de Salazar, A. Soria, M.I. Barrena, Corrosion behaviour of Cu-based shape memory alloys, diffusion bonded, J. Alloys Comp. 387 (2005) 109-114.

[3] A.T. Adorno, R.A.G. Silva, Isothermal decomposition kinetics in the $\mathrm{Cu}-9 \% \mathrm{Al}$ 4\%Ag alloy, J. Alloys Comp. 375 (2004) 128-133.

[4] A.T. Adorno, R.A.G. Silva, A.G. Magdalena, Thermal behavior of $\alpha-(\mathrm{Cu}-\mathrm{Al}-\mathrm{Ag})$ alloys, J. Therm. Anal. Calorim. 87 (3) (2007) 759-762.

[5] E. Obradó, C. Frontera, L. Manosa, A. Planes, Order-disorder transitions of CuAl-Mn shape memory alloys, Phys. Rev. B: Condens. Matter Mater. 58 (1) (1998) 14245-14255.

[6] R. Kainuma, S. Takashi, K. Ishida, Thermoelastic martensite and shape memory effect in ductile Cu-Al-Mn alloys, Metall. Mater. Trans. A 27 (8) (1996) 2187-2195.
[7] R. Kozubski, J. Soltys, Decomposition of $\beta$-phase in the Heusler alloy $\mathrm{Cu}_{2.00} \mathrm{Mn}_{1.00} \mathrm{Al}_{1.00}$, J. Mater. Sci. 17 (1982) 1441-1446.

[8] Y. Sutou, N. Koeda, T. Omori, R. Kainuma, K. Ishida, Effects of ageing on bainitic and thermally induced martensitic transformations in ductile $\mathrm{Cu}-\mathrm{Al}-\mathrm{Mn}$ based shape memory alloys, Acta Mater. 57 (2009) 5748-5758.

[9] S. Vyazovkin, A.K. Burnham, J.M. Criado, L.A. Pérez-Maqueda, C. Popescu, N. Sbirrazzuoli, ICTAC kinetics committee recommendations for performing kinetic computations on thermal analyses data, Thermochim. Acta 520 (2011) 1-19.

[10] S. Vyazovkin, C.A. Wight, Kinetics in solids, Ann. Rev. Phys. Chem. 48 (1997) 125-149. 